\title{
INCREASING THE SOCIAL EFFECTIVENESS OF PUBLIC TRANSPORT
}

\section{Svetla Tzvetkova ${ }^{1}$}

\begin{abstract}
The functioning of public transport as a primarily social phenomenon leads to the realization of a significant social effect. The more deployed and high-quality the level of transportations is, the larger the social effect is. This also elevates the culture of passenger service and the use of modern environmentally friendly means of transport. The social effect has a multilateral manifestation, but the most significant one is its manifestation in the following trends: satisfying the population's various travel needs; reducing travel time and increasing free time, thus increasing the time for rest, relaxation, entertainment, educational and sport activities. The social effect is also achieved through the use of modern and environmentally friendly means of transport with reduced harmful emissions and noise impact on the population's health. The primary goal of socially effective public transport is to be accessible to everyone, to provide comfort, awareness, safety and security during passenger travel by incorporating efficient and stable urban intelligent transport systems and modern integrated environmentally friendly public transport with better emission indicators. The present report is dedicated to the main trends of increasing the social effectiveness of public transport in cities.
\end{abstract}

JEL Classification Numbers: R41; DOI: http://dx.doi.org/10.12955/cbup.v5.971

Keywords: public transport, social effectiveness, quality transport, stable urban transport systems

\section{Introduction}

Increasing the social effectiveness of public transport has a defining role in the social and economic development of major cities. Quality transport contributes to the improvement of cultural and economic relations between separate regions, the trouble-free transportation of passengers for production needs and personal needs, and it becomes a basis for enhancing citizens' living conditions and standard. The issue of the social effectiveness of public transport and the quality of freights has become particularly topical in recent years. Because the dynamic of urban traffic and the growing number of personal vehicles are the main reasons for traffic jams in European metropolises and environmental pollution with about $40 \%$ of $\mathrm{CO}_{2}$ emissions and $70 \%$ of other air pollutant emissions, the European Commission has unsurprisingly focused on these problems, compiling the Green Book of Urban Mobility. It is a global strategy that defines the challenges that European cities face in their drive to provide stable mobility and social effectiveness by facilitating traffic in cities, reducing environmental pollution and noise and improving the organization, accessibility, security and safety of public transport.

The primary objectives of public transport in major European cities have to be: increasing social effectiveness through the use of higher-quality and more environmentally friendly transport; convincing citizens to use their personal cars less and aim at using public transport more frequently; fully satisfying their needs and covering their criteria for high-quality transport services.

\section{Social effectiveness and quality of public transport}

The social effectiveness of public transport is shown in the results of expenses for achieving a certain social effect. The results related to the degree of satisfying citizens' needs for public transport are regarded as social effects. The higher the quality of public transport, the higher its social effectiveness (Vasilev, 1997).

European standard EN 13816 (2003) defines the indicators for measuring the quality of public transport: time, availability, accessibility, comfort, information, customer care, safety and security, influence on the environment (pollution and noise).

It is especially important that firms dealing with transport services strive to fully satisfy users' needs and, ideally, attempt to offer them such quality that best suits their needs. Therefore, the target quality of the service has to be as close to customers' marketing criteria and their ideas of higher-quality transport services as possible. The literature does not provide a uniform standpoint on the hierarchy of individual indicators measuring the quality of public transport due to the subjective nature of satisfying travel needs, which means that it not always accurately defined or simple. People from different cities and states can have different habits, traditions and expectations regarding quality. The hierarchy of consumer criteria in regards to satisfying needs is a variable because customer expectations are not consistent and they can become larger, depending on the advancement in other sectors (for example, by

${ }^{1}$ UNWE - Sofia, svetlatzvetkova@abv.bg 
introducing new technology, air conditioning and increasing comfort standards).

However, there is a uniform opinion in transport literature about the degree of importance of the "time" indicator, or the quantity of time spent on traveling with public transport is accepted as defining the quality of the service. Another important indicator directly linked to time is the "availability" indicator, which defines the degree of regularity of vehicle movement on preliminarily defined routes, which is determined by the available and planned in the schedule number of vehicles, especially in the peak periods of the day. Transport operators have to keep a constant eye on the percentage of trains traveling on time; the threshold of delay has to be between 2.5 to 5 minutes. The percentage of freight regularity has to be $97-98 \%$ in order to achieve the necessary quality of urban population service. This is especially important due to the circumstance that irregularity in public transport vehicle traffic is linked to a number of negative consequences.

In order for urban passenger traffic to be appealing, it has to be both regular and easily accessible to all passengers; $96 \%$ of the passengers cannot waste a lot of time and they need to have easy access to vehicles. Accessibility concerns primarily people with impeded mobility, disabled people, elderly people, families with small children who need to have easy access to the infrastructure of public transport as well as to automatic ticket machines.

The "comfort during trips" indicator is defining for the quality of public transport in Europe's larger capitals. Comfort while traveling usually means the number of people per square meter. According to the standard in peak urban transport moments, the number of passengers per square meter cannot exceed four people (Mutafchiev, 2000). Creating conditions for a comfortable and pleasant travel experience also suggests that the temperatures and the level of cleanliness in vehicles have to be in accordance with the preliminarily defined standards.

The "awareness" indicator is also vital to quality customer service. Traveling citizens have to be kept updated on current information about the vehicle schedules at stations, stops and the vehicles themselves, as well as receive timely and immediate information about impending delays or irregularity of vehicles in case an operator's performance is impaired.

Caring about customers' satisfaction with transport services has to be a priority of transport operators carrying out passenger freights, which is another important indicator regarding the level of the provided transport service. The company has to keep an eye out for incoming citizen complaints and adopt quick and appropriate measures to remove the problems that arise during or in relation to freights.

The "traffic safety and security" indicator also determines a large portion of citizens' decisions to use one mode of transportation or another. Safe and accident-free travel, as well as maintaining the security and peace of citizens during trips is one of the most important indicators regarding the degree of quality of public transport.

\section{Directions for increasing social effectiveness}

In order to increase the social effectiveness of public transport, public transporters have to adopt effective measures for increasing the quality of the transport services they offer. Public transport enterprises have to successfully convince citizens to use public transport through the high-quality transport services they offer and make them aware of its social effects. In order to achieve this, they have to reduce the travel time and provide comfortable, secure and environmentally friendly public transport. This can be achieved through introducing modern high-speed vehicles into service, increasing the number of public transport routes and the availability, regularity and rhythm of vehicles, especially in the peak and most bearing periods of the day.

The necessity to modernize urban infrastructure so it corresponds with the city's needs is crucial to increasing the quality of public transport freights. Modern stops equipped with information panels need to be built. It is necessary for the city to be equipped with available parking lots near subway stations, next to which there need to be parking spaces for bicycles. Access to bus or tram transport has to be provided next to each subway station. Trams are preferable because of their high environmental friendliness and passenger capacity. Overall, in order to increase the quality of public transport and reduce travel time, it is necessary to improve intermodal connections and create more comfort during the whole trip. However, one of the most important issues related to the effective functioning of urban passenger transport is coordinating the work of its separate types. The good integration of the work of different urban passenger transport types is a good prerequisite for improving the transport service of 
the population, which simultaneously creates an opportunity for the most rational use of transport vehicles possible.

The safety and security of stations, stops and vehicles has to be at the necessary level for both passengers and vehicle drivers, i.e. by introducing a security strategy through equipping stops and vehicles with cameras and creating better safety conditions for stations and the surrounding territories. Regular security and safety training also have to be organized, as well as increasing vigilance.

Traffic safety has primary significance for secure passenger trips with public transport. The main trends of increasing vehicle reliability and traffic safety are aimed at updating vehicles and increasing drivers' qualification. A typical trait of transport manufacturing activity is that its nature is too cyclic

and it is directly related to the specifics of transport and the probability for the occurrence of risky situations and traffic accidents. Its employees are required to have more specific qualities and skills which are necessary during the sometime extreme situations that arise during work. Transport workers have to be able to react quickly and appropriately; sometimes, within a very limited time frame, they have to make important and responsible decisions upon which people's lives depend. In addition to high qualification and professionalism, it is necessary for transport employees to possess other qualities such as high psychological stability.

In addition, the rolling stock within the public transport system has to be modernized constantly. The rolling stock has to be renewed gradually, with vehicles with modern technical characteristics and high parameters of comfort and environmental friendliness, which will increase comfort and safety during travel and will remove even the smallest prerequisites for the occurrence of traffic accidents. By introducing modern, environmentally friendly and energy-saving vehicles into service, better environmental parameters will be reached, such as air quality and harmful emissions, reduction of pollution, greenhouse effect and energy consumption; noise reduction and climate change are necessary for improving the population's health status and reducing healthcare expenses.

It is necessary to implement intelligent transport systems which will aid public transport management and organization in major cities. Their implementation can improve cities overall vision and image. These are innovative and modern decisions that guarantee bigger safety and security for citizens and can improve their living standards as a whole. They can improve significantly traffic situation in cities, make various urban zones more accessible and secure access to work places and services for all citizens. The appeal and quality of the urban environment can be improved as a whole.

Based on operational experience, some of the benefits of implementing intelligent transport systems are measured quantitatively, with regard to the following key aspects of exploitation concerning the city of Sofia: management of the network and road safety.

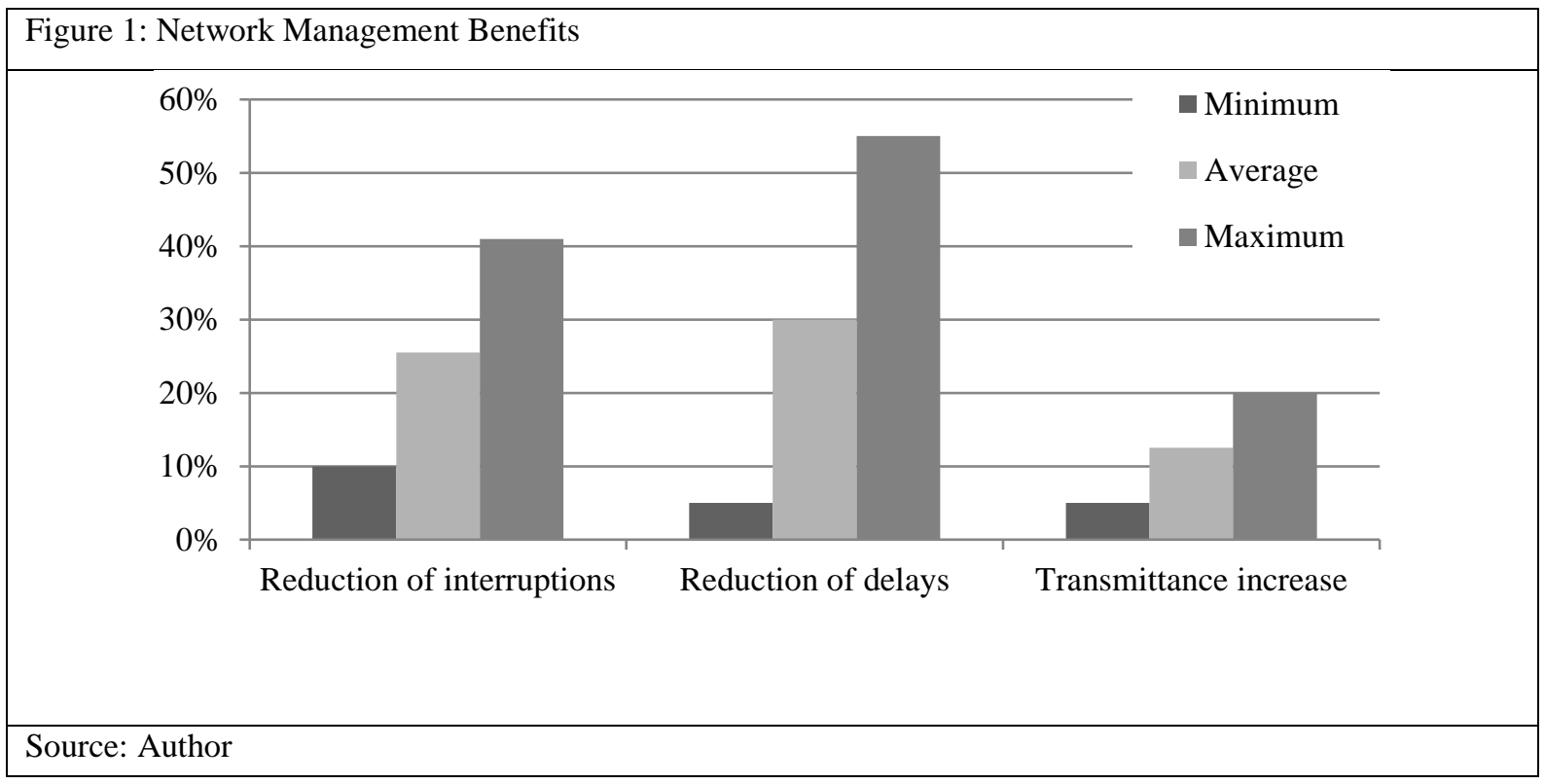




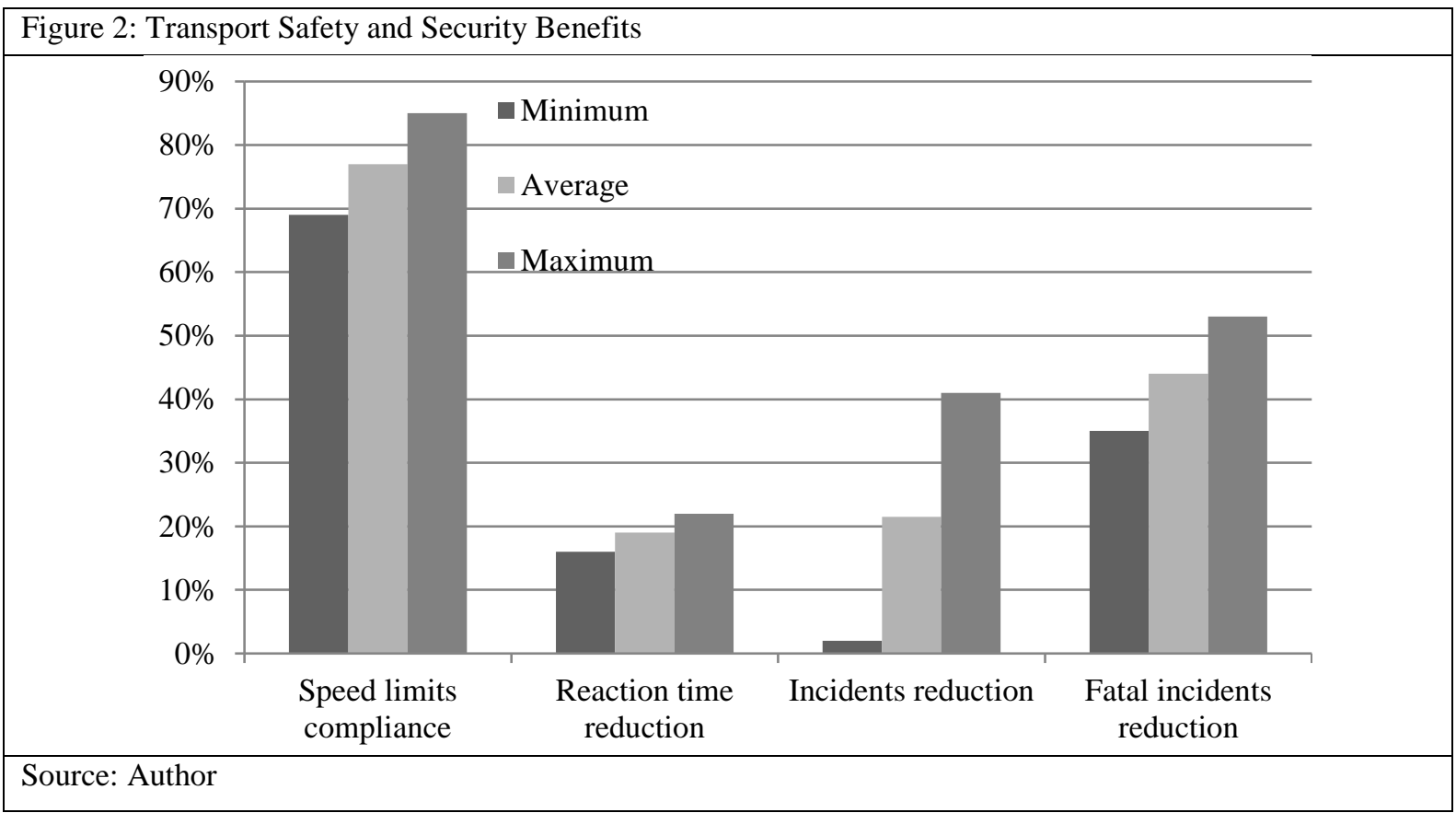

The incorporation of such systems can reduce travel time by about $20 \%$, greenhouse gas emissions from cars by about $15 \%$, improve public transport traffic observation by $40 \%$ and reduce traffic accidents by about 35\% (Strategy for ITS development for Sofia, 2010).

Increasing the social effectiveness and partially the quality of urban passenger transport has to be aimed at current and potential users, with the primary beneficiaries being passengers with impeded mobility, elderly people and families with children. Safety and security measures also have to be introduced for the protection of public transport drivers. It is advisable to analyze the current situation of supply and demand in public transport and to identify the zones that are inaccessible or are sparsely visited through public transport. Preliminary marketing studies are also necessary to determine the specific demands and needs of target groups as well as the political support and willingness of local decision-making authorities to change the way that public transport is perceived and supported in order to stimulate different target groups to use this form of transportation.

\section{Conclusion}

The development of socially effective and integrated public transport is in accordance with the EU's transport policy for achieving urban mobility of citizens. It involves encouraging the use of environmentally friendly transport, providing accessibility and mobility for citizens and reducing the use of their personal vehicles. International experience shows that in regards to company management in the field of urban bus transport, the measures for improving electronic billing, car pool management, providing passengers with information, right of way at intersections with traffic light regulation, etc. can lead to significant results when it comes to increasing the number of travels (passengers) by public transport (Gatovski, 2016). This will guarantee successful economic and social development for cities, high quality of life for their citizens, traffic jam reduction and environmental protection. Special attention is given to the provision of higher-quality and more accessible public transport for disadvantaged people, people with impeded mobility, disabled people, elderly people, families and small children.

\section{References}

European Standard EN 13816: 2003;

Gatovski, I. (2016) Analysis of the state and primary trends in the development of public transport in Sofia - Mobility for a connected world-Research-and-Practice Conference, UNWE (October 2016);

Mutafchiev, L. (2000) Organization of Urban Passenger Transport, UE “Stopanstvo”, Sofia;

Strategy for ITS development for Sofia (November 2010).

Vasilev,E. (1997) Development and Effectiveness of Passenger Freights, UE "Stopanstvo", Sofia 